\title{
Prevention of Pesticide Toxicity Risk through the Farmer Community Movement to Resolve Toxicity
}

\author{
Eka Lestari Mahyuni ${ }^{*}$, R. Hamdani Harahap ${ }^{2}$, Urip Harahap ${ }^{3}$, Nurmaini \\ ${ }^{1}$ Departemen Keselamatan dan Kesehatan Kerja, Fakultas Kesehatan Masyarakat, \\ Universitas Sumatera Utara \\ ${ }^{2}$ Departemen Antropologi Sosial, Fakultas Ilmu Sosial dan Ilmu Politik, Universitas Sumatera \\ Utara \\ ${ }^{3}$ Departemen Farmasi, Fakultas Farmasi, Universitas Sumatera Utara \\ ${ }^{4}$ Departemen Kesehatan Lingkungan, Fakultas Kesehatan Masyarakat, Universitas Sumatera \\ Utara \\ *Email: eka.lestari@usu.ac.id
}

\begin{abstract}
Pesticide toxicity is a phenomenon that needs to be prevented, which is generally caused by the risky behavior of using pesticides. This PPM activity is one of the community empowerment activities to reduce the risk of pesticide toxicity through the GEMPAR (Gerakan Masyarakat Petani Atasi Racun) action. GEMPAR consists of eight farmer movements to prevent the risk of toxicity due to pesticides used. The eight GEMPAR actions were applied by farmers with promotional and educational methods through the GEMPAR demonstration activities. The demonstration implementation method is presented by the farming community which is divided into three areas in Sumber Mufakat Village, namely Berhala, Simpang Sumbul, and Pasar Sumbul. Demonstrations from these three areas were contested as a form of appreciation for the community so that they could motivate the community to participate in preventing the risk of pesticide toxicity. The demonstration that displayed the messages of the eight GEMPAR movements was carried out well. Each demonstration gives special characteristics either through songs or slogans related to preventing the risk of toxicity. The community became very enthusiastic about the demonstration which could increase the participation of the farming community to use better and healthier pesticides sustainably.
\end{abstract}

Keyword: empowerment, farmers, GEMPAR, pesticides, demonstration

\begin{abstract}
Abstrak
Keracunan pestisida merupakan fenomena yang perlu dicegah yang umumnya disebabkan karena perilaku penggunaan pestisida yang berisiko. Kegiatan PPM ini merupakan salah satu kegiatan pemberdayaan masyarakat untuk mengurangi risiko keracunan pestisida melalui aksi GEMPAR (Gerakan Masyarakat Petani Atasi Racun). GEMPAR terdiri dari delapan gerakan petani untuk mencegah risiko keracunan akibat penggunaan pestisida. Delapan aksi GEMPAR diaplikasikan oleh petani dengan metode promosi dan edukasi melalui kegiatan demonstrasi aksi GEMPAR. Metode pelaksanaan demonstrasi disajikan oleh masyarakat petani yang terbagi dalam tiga area yang ada di Desa Sumber Mufakat yaitu Berhala, Simpang Sumbul, dan Pasar Sumbul. Demonstrasi dari ketiga area ini dilombakan sebagai bentuk apresiasi untuk masyarakat sehingga dapat memotivasi masyarakat untuk berpartisipasi dalam mencegah risiko keracunan pestisida. Aksi demonstrasi yang menampilkan pesan-pesan delapan gerakan GEMPAR terlaksana dengan baik. Dari tiap demonstrasi memberikan ciri khas khusus baik melalui lagu ataupun slogan terkait mencegah risiko keracunan. Masyarakat menjadi sangat antusias dengan aksi demonstrasi yang dapat meningkatkan partisipasi masyarakat petani untuk menggunakan pestisida lebih baik dan sehat secara berkelanjutan.
\end{abstract}

Kata Kunci: pemberdayaan, petani, GEMPAR, pestisida, demonstrasi 
Eka Lestari Mahyuni dkk. Prevention of Pesticide Toxicity Risk through the Farmer Community Movement to Resolve Toxicity

\section{PENDAHULUAN (INTRODUCTION)}

Kabupaten Karo merupakan salah satu wilayah dataran tinggi yang terkenal sebagai sentra pertanian khususnya sayur-mayur dan buah-buahan. Wilayah dengan dua gunung vulkanik yaitu Gunung Sinabung dan Gunung Sibayak membuat daerah ini terkenal sebagai lahan yang subur. Banyak wisatawan yang menikmati hawa sejuk pegunungan terutama di dua daerah yaitu Berastagi dan Kabanjahe. Kabanjahe merupakan ibu kota Kabupaten Karo dan secara administratif merupakan kecamatan yang menaungi 8 desa salah satunya Desa Sumber Mufakat yang merupakan lokasi kegiatan PPM.

Masyarakat Desa Sumber Mufakat sering dikenal sebagai petani bunga karena mayoritas area pertanian menghasilkan bunga dan tanaman hortikultura yaitu tanaman sayur-sayuran dan buahbuahan. Penggunaan pestisida pada tanaman ini umumnya memiliki frekuensi yang sangat tinggi karena tanaman ini sangat rawan terhadap hama (Badan Pusat Statistik Kabupaten Karo, 2018; Mahyuni, Harahap, Harahap, \& Nurmaini, 2019; Mahyuni, Yustina, \& Sudaryati, 2017; Mahyuni \& Sinaga, 2016).

Berdasarkan hasil wawancara dengan Dinas Kesehatan angka keracunan tertinggi di tahun 2020 adalah di Kecamatan Tiga Panah dan Kabanjahe. Data kejadian yang dirujuk ke rumah sakit umumnya karena terpapar dengan herbisida seperti Gramaxon. Berdasarkan hasil observasi dan wawancara dalam menggalang kemitraan, masalah keracunan masih menjadi catatan di Desa Sumber Mufakat. Pada dasarnya banyak petani yang terpapar secara langsung pada saat menyemprot pestisida karena tidak menggunakan APD. Percikan juga sering mengenai mata, wajah, kulit bahkan terhirup. Hal ini sangat berbahaya karena secara kumulatif masuknya pestisida ke dalam tubuh dapat menimbulkan keracunan. Disamping itu tanaman yang tinggi juga membuat petani tidak dapat menghindari jatuhnya semprotan pestisida mengenai tubuhnya (Gambar 1.1) (Mahyuni, 2015; Rumah Sakit Umum Kabanjahe, 2018).

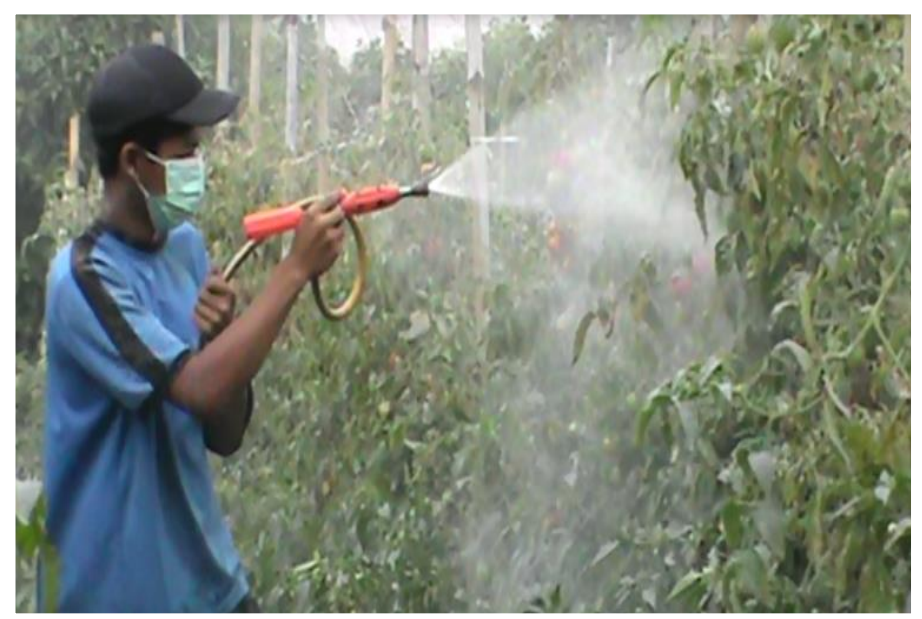

Gambar 1.1 Penggunaan Pestisida yang Berbahaya

GEMPAR (Gerakan Masyarakat Petani Atasi Racun) merupakan suatu program intervensi kesehatan yang disusun untuk menyelesaikan setiap determinan dari proses penggunaan pestisida yang tidak sesuai prosedur. Melalui GEMPAR masyarakat diajak untuk berpartisipasi langsung memelihara kesehatannya dengan mengurangi risiko keracunan. GEMPAR terurai dalam 8 (delapan) langkah intervensi yaitu 1). Kenali bahaya racun pestisida; 2). Gunakan pelindung diri yang lengkap; 3). Perhatikan arah angin dan rote penyemprotan; 4). Simpan pestisida di tempat yang aman dan tertutup; 5). Buang sisa kemasan pestisida di tempat tertutup; 6). Bersihkan diri setelah menyemprot (personal hygiene); 7). Catat dan lapor keluhan keracunan segera; dan 8). Beralih ke pertanian organik. 
Eka Lestari Mahyuni dkk. Prevention of Pesticide Toxicity Risk through the Farmer Community Movement to Resolve Toxicity

\section{METODE PELAKSANAAN (METHODS)}

Metode pelaksanaan aksi GEMPAR pada kegiatan PPM ini dilaksanakan dalam beberapa tahap sebagai berikut:

\section{Tahap 1. Sosialisasi Aksi GEMPAR di Desa Sumber Mufakat}

Pada tahap ini tim PPM melakukan kegiatan sosialisasi dengan masyarakat petani hortikultura, komunitas GEMPAR sebagai komunitas peduli racun serta stakeholder yaitu pemerintahan setempat. Metode pelaksanaan sosialisasi yaitu Focus Group Discussion (FGD) bersama masyarakat petani dan rapat bersama stakeholder dan masyarakat (brainstorming).

\section{Tahap 2. Pelaksanaan GEMPAR di Desa}

Pelaksanaan GEMPAR dilakukan secara serentak pada jadwal yang telah ditetapkan tim PPM dengan masyarakat dan perangkat Desa setempat. Pelaksanaan GEMPAR dilakukan sebagai upaya promosi gerakan aksi pencegahan risiko keracunan pestisida. Bentuk kegiatan yang dilakukan adalah Perlombaan Demonstrasi Aksi GEMPAR.

Kegiatan perlombaan demonstrasi aksi GEMPAR merupakan kegiatan masyarakat petani untuk mengenalkan dan mempromosikan aksi GEMPAR melalui demonstrasi yang diperagakan dan memuat pesan delapan aksi GEMPAR. Demonstrasi ini akan dilombakan untuk mengapresiasi inovasi dan metode penyampaian pesan pencegahan risiko keracunan pestisida.

\section{Tahap 3. Tahap Evaluasi Kegiatan PPM}

Evaluasi kegiatan PPM dalam mempromosikan aksi GEMPAR sebagai program pencegahan pestisida dilakukan dengan memenuhi indikator keberhasilan program yaitu semakin meningkatnya masyarakat yang berpartisipasi mencegah risiko keracunan pestisida. Indikator keberhasilan dari demonstrasi aksi GEMPAR adalah tercapainya pesan pencegahan keracunan pestisida melalui slogan-slogan khusus yang jadi pedoman bagi masyarakat petani untuk mencegah risiko keracunan pestisida.

\section{HASIL DAN PEMBAHASAN (RESULT AND DISCUSSION)}

Penggunaan pestisida pada petani Karo umumnya sangat berlebihan dan sering terjadi kontak langsung dengan pestisida karena petani tidak menggunakan pelindung diri. Petani selalu mengabaikan paparan ini sehingga efek akut dan kronis sangat berpotensi terjadi. Pestisida sudah menjadi kebutuhan untuk menyokong kehidupan petani sehingga menjadi mata pencaharian utama petani. Di sisi lain, paparan pestisida secara kronis berisiko tinggi mengalami penyakit seperti kanker, kelelahan atau musculoskeletal disorders (MSDs), penyakit degeneratif, dan risiko kematian (Alavanja, Hoppin, \& Kamel, 2004; Arcury \& Quandt, 2003; Deborah, 2006; Engel et al., 2005; Mahyuni, 2015; Mahyuni \& Sinaga, 2017; Quijano, R., \& Sarojeni, 1999; Yuantari, Widianarko, \& Sunoko, 2015).

Kebiasaan menggunakan pestisida yang tidak sesuai merupakan hal biasa bagi petani. Terciprat, tersentuh, bahkan makan sebelum mencuci tangan setelah kontak dengan pestisida sering dilakukan petani. Gejala dan keluhan juga sering dirasakan petani seperti kulit gatal, panas, memerah, mata pedih, dan rasa lelah yang sangat setelah menyemprot pestisida. Oleh karena itu masyarakat petani yang belum produktif ini harus ditingkatkan melalui pemberdayaan masyarakat melalui gerakan masyarakat yang disebut dengan GEMPAR (Gerakan Masyarakat Petani Atasi Racun).

\subsection{Sosialiasi Delapan Langkah Aksi GEMPAR sebagai Program Pencegahan Risiko Keracunan Pestisida}

Sosialiasi dilakukan bersama masyarakat petani selaku pemeran utama yang diharapkan dapat berdaya dalam meningkatkan kesehatannya sebagai petani. Fokus kegiatan pemberdayaan ini juga melibatkan komunitas GEMPAR yang telah terbentuk sebagai komunitas peduli racun. Delapan gerakan dari GEMPAR disampaikan sebagai informasi dan promosi pada masyarakat di Desa Sumber Mufakat. Berdasarkan hasil brainstorming dan advokasi dengan pemerintahan setempat, 
kegiatan demonstrasi dapat dilakukan dan hasil rembug memutuskan dilaksanakan di ladang salah satu petani. Aksi demonstrasi juga merupakan aksi bagaimana mempromosikan delapan gerakan pencegahan risiko keracunan pestisida. Demonstrasi akan ditampilkan dalam berbagai cara yang menjadi inovasi masyarakat dari tiga area Desa Sumber Mufakat yaitu Berhala, Simpang Sumbul, dan Pasar.

\subsection{Perlombaan Demonstrasi Aksi GEMPAR dalam Mencegah Risiko Keracunan Pestisida}

Kegiatan PPM ini adalah melombakan pesan aksi GEMPAR sebagai program pencegahan risiko keracunan pestisida. Aksi GEMPAR memuat delapan gerakan yang diperankan masyarakat petani sebagai program pencegahan risiko keracunan pestisida. Demonstrasi yang dilakukan petani merupakan aksi-aksi promosi yang diciptakan sendiri oleh agen-agen pemberdaya yang telah dibentuk sebagai komunitas GEMPAR oleh tim PPM sebelumnya.

Pemberdayaan masyarakat membutuhkan pelaku yang memiliki kompetensi dan kredibilitas yang baik. Landasan dasar dari hal ini adalah adanya agen-agen pengubah (agent of change) yang berkomitmen dalam upaya pemberdayaan masyarakat untuk meningkatkan kesehatan dan kesejahteraan petani. Agen pengubah yang berkomitmen dan dapat dipercaya oleh masyarakat setempat sangat berperan untuk mempercepat perubahan sosial yang diharapkan. Agen pengubah merupakan sosok yang dapat membantu petani mulai dari tahap perencanaan hingga evaluasi dari setiap program yang dijalankan. Agen pengubah juga dapat bekerjasama dan mendampingi masyarakat serta membina masyarakat sehingga perubahan sosial yang diharapkan tercapai. Kesuksesan peran agen pengubah tergantung pada beratnya kualitas dan kemampuan kerja dari hubungan kerjasama antara agen pengubah dan pengambil keputusan (key decision maker) (Amalia, Dayati, \& Nasution, 2017; Lunenburg, 2010; Mardikanto, 2010; Suryana, Sugiana, \& Trulline, 2016).

Demontrasi yang dilakukan dikemas masyarakat dalam bentuk drama parodi yang menggambarkan kebiasaan penggunaan pestisida sehari-hari. Parodi tersebut memuat delapan aksi GEMPAR karena antar petani menyampaikan pesan-pesan pencegahan demi kebaikan, keselamatan, dan kesehatan petani selama menggunakan pestisida. Demonstrasi disajikan oleh 3 kelompok yang mewakili tiga area di Desa Sumber Mufakat yaitu area Berhala, Simpang Sumbul, dan Pasar Sumbul.

\subsubsection{Demonstrasi Area Berhala Desa Sumber Mufakat}

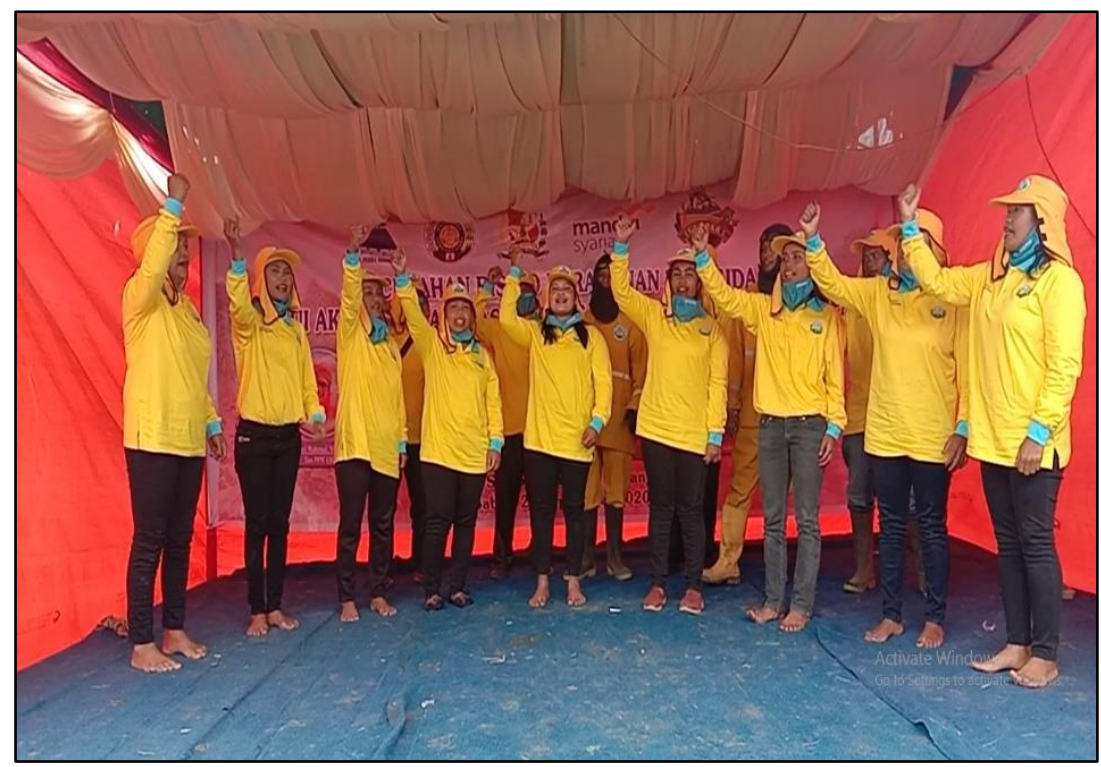

Gambar 3.1 Kelompok Area Berhala 
Kelompok area Berhala menyajikan pesan GEMPAR melalui drama edukasi dengan melakukan pengarahan pada masyarakat yaitu menyampaikan pesan pencegahan penggunaan pestisida yang tidak sesuai. Pemakaian pestisida yang tidak baik diantaranya penggunaan 2-3 pestisida dengan bahan aktif yang sama dalam sekali pemakaian sehingga dosisnya menjadi berlebihan, tidak digunakannya APD, tidak pernah mencuci tangan, dan tidak perhatikan arah angin. Hal yang tidak baik ini diarahkan untuk diperbaiki dengan pesan edukasi dan memperhatikan delapan aksi GEMPAR yang dikenalkan sehingga masyarakat agar dapat mengubah perilakunya selama menggunakan pestisida. Pada penampilan aksi demonstrasi masyarakat Berhala menyajikan pesan-pesan pencegahan melalui lagu yang diciptakan dan liriknya sesuai dengan pesan aksi GEMPAR. Lagu ini diciptakan agar memudahkan masyarakat Berhala mengingat delapan aksi GEMPAR sehingga area Berhala menjadi petani yang sehat selama menggunakan pestisida.

\subsubsection{Demonstrasi Area Simpang Sumbul Desa Sumber Mufakat}

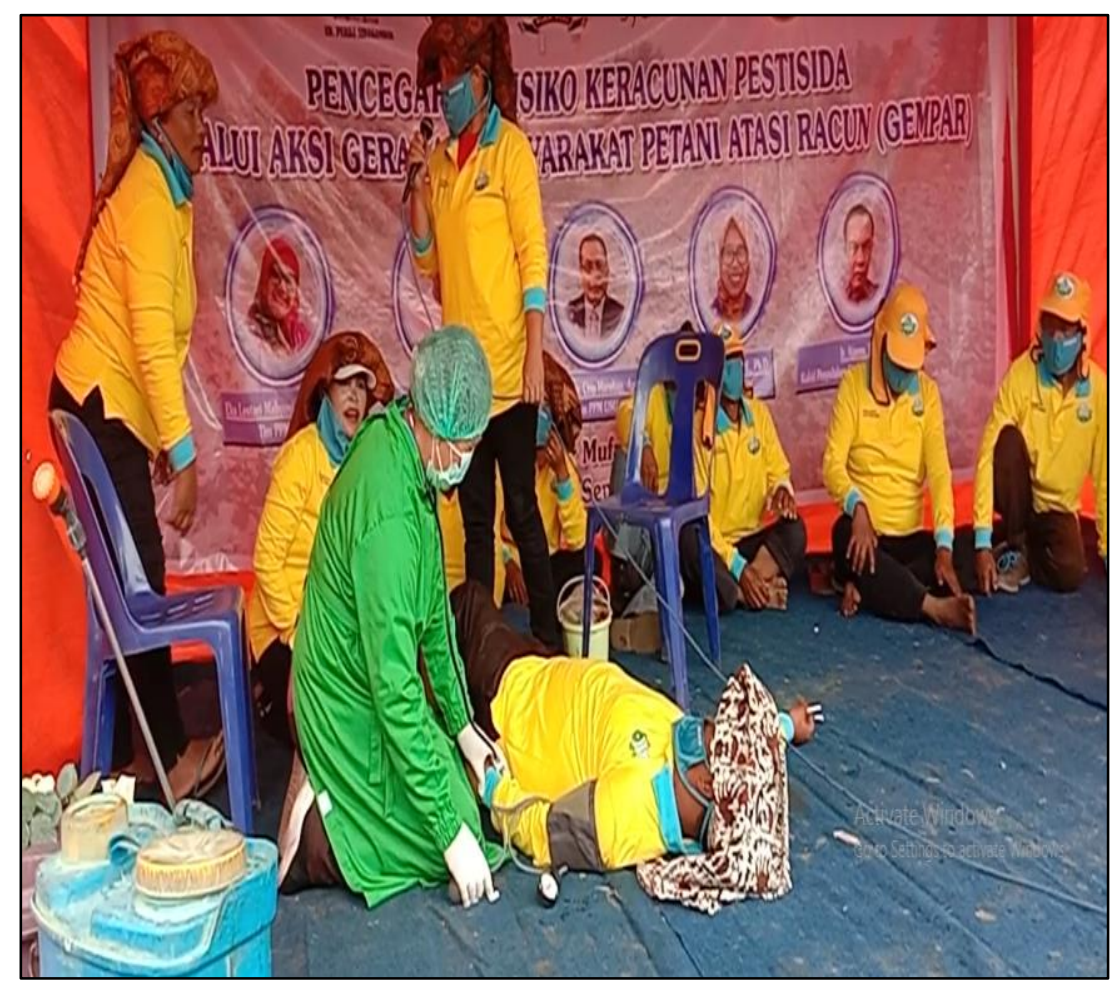

Gambar 3.2 Demonstrasi Area Simpang Sumbul

Area Simpang Sumbul mendemonstrasikan aksi GEMPAR melalui drama edukasi yang sesuai dengan pemakaian pestisida sehari hari. Penekanan pesan dari parodi yang dilakukan ditekankan pada bahaya bahan aktif dari pestisida yang digunakan serta penggunaan APD yang lengkap untuk menghindari kontak langsung dengan pestisida. Disamping itu penampilan demonstrasi ini juga sudah mengarahkan petani untuk beralih ke pertanian organik karena tingginya risiko bahan aktif yang selama ini sering digunakan sehingga didemonstrasikan suami petani yang mengalami keracunan hingga mengalami koma. Penyampaian pesan juga sangat sederhana dan mudah dicerna masyarakat petani mulai dari nama kelompok yang diberi nama MAWAR singkatan dari MAsyarakat Wajib Atasi Racun. Ide ini berpedoman pada aksi GEMPAR sehingga memudahkan masyarakat mengingat kewajiban mencegah keracunan sebagai wujud berpartisipasi dalam aksi GEMPAR. Slogan yang disampaikan juga mengikuti visi dari GEMPAR yaitu Petani Sehat Tanpa Pestisida. 
Eka Lestari Mahyuni dkk. Prevention of Pesticide Toxicity Risk through the Farmer Community Movement to Resolve Toxicity

\subsubsection{Demonstrasi Area Pasar Desa sumber Mufakat}

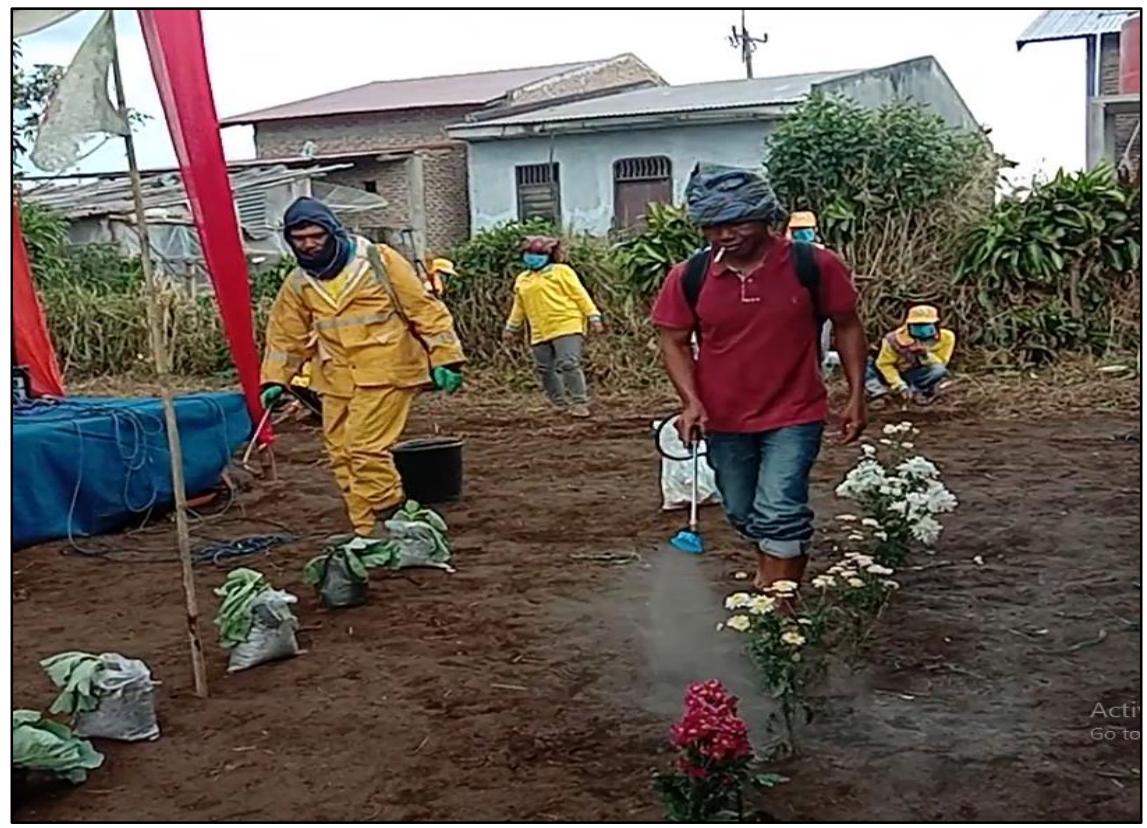

Gambar 3.3 Demonstrasi Area Pasar

Area Pasar juga menampilkan parodi edukasi yang menjelaskan delapan aksi GEMPAR dan memuat sedikit komedi di beberapa segmen drama yang disajikan. Partisipan demonstrasi dari area Pasar juga menggunakan beberapa atribut alami seperti tanaman bunga dan sayur-sayuran, memakai sarung, dan pestisida yang biasa digunakan, sehingga menunjukkan latar yang mirip seperti keadaan asli. Pasar merupakan slogan yang disajikan kelompok ini yaitu singkatan dari Petani Sehat Atasi Racun. Dalam penampilannya kelompok demonstrasi Pasar menjelaskan perbedaan antara petani yang masih salah dalam penggunaan pestisida dan petani yang benar dalam penggunaan pestisida. Penyajian yang tampak alami dilakukan menunjukkan perbedaan sebab dan akibat dari penggunaan pestisida sesuai prosedur dengan yang tidak sesuai prosedur. Dalam penampilannya kelompok ini menjelaskan pesan-pesan singkat pentingnya delapan aksi GEMPAR sebagai program pencegahan keracunan pestisida. Slogan yang disampaikan kelompok ini adalah "PASAR - Petani Sehat Atasi Racun, Mejuah juah "Bersama Kita Bisa" Pesan pesan ini menunjukkan gerakan yang positif dan mudah untuk diterima masyarakat agar bersama sama mencegah risiko keracunan pestisida.

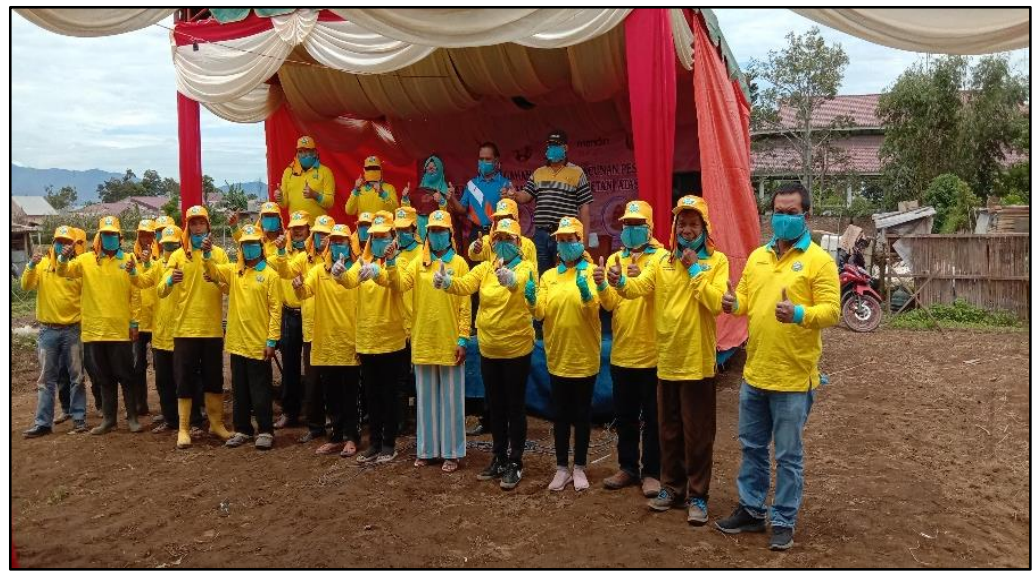

Gambar 3.4 Foto Bersama Kepala Desa dan Komunitas GEMPAR 
Eka Lestari Mahyuni dkk. Prevention of Pesticide Toxicity Risk through the Farmer Community Movement to Resolve Toxicity

\section{KESIMPULAN (CONCLUSION)}

Program pencegahan risiko keracunan pestisida telah berhasil dilaksanakan dengan baik. Indikator keberhasilan yang dicapai melaui kegiatan demonstrasi yang dilakoni petani mampu mempromosikan delapan aksi GEMPAR melalui slogan-slogan yang mudah diterima sehingga masyarakat menjadi sadar dan mau menerapkan GEMPAR ke depan secara berkelanjutan. Partisipasi masyarakat Desa Sumber Mufakat untuk mencegah risiko keracunan pestisida semakin meningkat dan menjadi suatu kebanggaan bagi masyarakat Desa Sumber Mufakat. Untuk mendukung program pencegahan ini maka dibutuhkan komitmen dan dukungan dari pemerintahan setempat untuk memberdayakan instansi terkait dalam mendukung mencapai petani yang sehat dan aman dari bahaya pestisida.

\section{UCAPAN TERIMAKASIH (ACKNOWLEDGMENTS)}

Terima Kasih disampaikan kepada Lembaga Pengabdian Masyarakat Universitas Sumatera Utara yang telah mendanai kegiatan ini dalam program ABDIMAS TALENTA dengan nomor kontrak 287/UN5.2.3.2.1/PPM/2020, tanggal 9 Juni 2020. Terima kasih juga kami sampaikan pada dukungan dan partisipasi Komunitas GEMPAR yang memberdayakan masyarakat petani dalam kegiatan PPM ini. Terima kasih juga pada pemerintahan setempat Bapak Dinis Karo Karo selaku Kepala Desa Sumber Mufakat, Bapak Ajaren dari Dinas Pertanian dan Bapak Bagekin Ginting dari Dinas Kesehatan. Terima kasih juga tim PPM sampaikan atas kerjasama segala pihak yang menyukseskan acara ini Bapak Boi Fernando, Bapak Harta Sinuhaji, Ibu Nurida, dan Bapak Japet Tarigan serta seluruh tim terkait.

\section{DAFTAR PUSTAKA (REFERENCES)}

Alavanja, M. C. R., Hoppin, J. A., \& Kamel, F. (2004). Health Effects of Chronic Pesticide Exposure: Cancer and Neurotoxicity. Annual Review of Public Health, 25(1), 155-197. https://doi.org/10.1146/annurev.publhealth.25.101802.123020

Amalia, N. F., Dayati, U., \& Nasution, Z. (2017). Peran Agen Perubahan dalam Pelaksanaan Program Pemberdayaan Masyarakat Pesisir Pantai Bajulmati Kabupaten Malang. Jurnal Pendidikan: Teori, Penelitian, Dan Pengembangan, 2(11), 1572-1576. https://doi.org/10.17977/JPTPP.V2I11.10249

Arcury, T. A., \& Quandt, S. A. (2003). Pesticides at Work and at Home: Exposure of Migrant Farmworkers. Lancet, 362(9400), 2021. https://doi.org/10.1016/S0140-6736(03)15027-1

Badan Pusat Statistik Kabupaten Karo. (2018). Kecamatan Kabanjahe dalam Angka 2018. Kabanjahe: Badan Pusat Statistik Kabupaten Karo.

Deborah, R. (2006). Are Pests the Problem or Pesticides. Biology Journal, 28(1), 6-7.

Engel, L. S., Hill, D. A., Hoppin, J. A., Lubin, J. H., Lynch, C. F., Pierce, J., ... Alavanja, M. C. (2005). Pesticide Use and Breast Cancer Risk among Farmers' Wives in the Agricultural Health Study. American Journal of Epidemiology, 161(2), 121-135. https://doi.org/10.1093/aje/kwi022

Lunenburg, F. C. (2010). Managing Change: The Role of the Change Agent. International Journal of Management, Business, and Administration, 13(1), 1-6.

Mahyuni, E. L. (2015). Faktor Risiko dalam Penggunaan Pestisida terhadap Keluhan Kesehatan pada Petani di Kecamatan Berastagi Kabupaten Karo 2014. Jurnal Kesmas, 9(1), 79-89.

Mahyuni, E. L., Harahap, H., Harahap, U., \& Nurmaini. (2019). Exposure to Pesticide among Farmers in Sumber Mufakat Village. Proceedings of the International Family Health (I-FaH) Conferencce, Malaysia Journal of Medicine and Health Sciences, 15(Supp 4).

Mahyuni, E. L., \& Sinaga, M. M. (2016). Keracunan Pestisida Berdasarkan Gejala Fisik dan Aktivitas Enzym Cholinesterase pada Petani di Desa Sumber Mufakat Kabanjahe. Prosiding Kongres Nasional Ikatan Ahli Kesehatan Masyarakat Ke-13 ( KONAS IAKMI XIII) “ Masyarakat Hidup 
Eka Lestari Mahyuni dkk. Prevention of Pesticide Toxicity Risk through the Farmer Community Movement to Resolve Toxicity

Sehat Dan Bahagia Dalam Mencapai Sasaran Pembangunan Berkelanjutan ( SDGs 2030) " Edisi Kedua, (November 2016). Makassar.

Mahyuni, E. L., \& Sinaga, M. M. (2017). Health Impact of Pesticide Using Method at Sprayed Worker Farmer in Sumber Mufakat Village, Karo. Advances in Health Sciences Research, 1, 285-289. https://doi.org/10.2991/phico-16.2017.28

Mahyuni, E. L., Yustina, I., \& Sudaryati, E. (2017). Safety Talk and Check to Prevent Pesticide Toxicity among Farmer. International Journal of Public Health Science (IJPHS), 6(4), 293-298. https://doi.org/10.11591/ijphs.v6i4.9113

Mardikanto, T. (2010). Model-Model Pemberdayaan Masyarakat Acuan Bagi Akademisi dan Praktisi Pemberdayaan Masyarakat. Surakarta: Sebelas Maret University Press.

Quijano, R., \& Sarojeni, V. R. (1999). AWAS! Pestisida Berbahaya Bagi Kesehatan. Yayasan Duta Awam, Pesticide Action Network Asia and the Pacific.

Rumah Sakit Umum Kabanjahe. (2018). Data Pasien Intoksikasi Periode Januari-Oktober 2017: Rekam Medik Rumah Sakit Umum Kabanjahe Kabupaten Karo. Kabanjahe.

Suryana, A., Sugiana, D., \& Trulline, P. (2016). Pengaruh Atribut Agen Perubahan (Agent of Change) Pendamping Program Keluarga Harapan (PKH) terhadap Perubahan Sikap Rumah Tangga Sangat Miskin (RTSM) peserta Program Keluarga Harapan (PKH) di Kabupaten Bandung. Jurnal Manajemen Komunikasi, 1(1), 5-41. https://doi.org/10.24198/jmk.v1i1.10061

Yuantari, M. C., Widianarko, B., \& Sunoko, H. R. (2015). Analisis Risiko Pajanan Pestisida terhadap Kesehatan Petani. Jurnal Kesehatan Masyarakat, 10(2), 239-245. https://doi.org/10.15294/kemas.v10i2.3387 